\title{
Çocuk Sağlığı ile Illgilenen Hekimlerin Uyku Konusundaki Farkındalıkları
}

\section{Awareness of Pediatric Health Care Providers in Regards of Sleep}

\author{
Suzan Gündüz, Esma Uşak* \\ Özel Batman Hastanesi, Pediatri Kliniği, Batman, Türkiye \\ *Özel Hekim
}

Öz

Amaç: Uyku, çocukların sağlıklı büyüme ve gelişmeleri için çok önemlidir. Bozulmuş veya yetersiz uyku çocukta morbidite ve mortaliteye yol açmakta, çocuğun ve ailesinin hayat kalitesini olumsuz etkilemektedir. Uyku bozuklukları çocuklarla ilgilenen hekimler tarafından daha kolay tanınmakla birlikte uyku problemlerinin tanısı atlanmakta, göz ardı edilmekte ve uygun bölümlere konsültasyonlar ve tedaviler yetersiz kalmaktadır. Bu çalışma ile ülkemizdeki çocuk sağlığı ile ilgilenen hekimlerin çocuklarda uyku konusundaki farkındalıklarını göstermek istedik.

Gereç ve Yöntem: Bu çalışmada Sosyal Pediatri Sempozyumu'na katılan aile hekimleri ve pediatristlere bir anket doldurtuldu.

Bulgular: Çalışmaya katılan 150 hekimin \%67,3'ü çocuk hekimi iken; \%32,7'si aile hekimi idi. Hekimlerin büyük çoğunluğu eğitim ve araştırma hastanesi veya üniversite hastanesinde çalışmakta idi. Hekimlerin \%65,3'ünün çocuğu olduğu ve bunların dörtte üçünün $(\% 76,5)$ çocuğunda uyku sorunu yaşadığı belirtilmiştir. Hekimlerin büyük bir çoğunluğu $(\% 87,3)$ her bir hastasına 15 dakikadan az vakit ayırmakta idi. Hekimlerin uyku konusunu hastaların çok az bir kısmıyla konuştuğu görülmektedir. Hekimlerin sadece \%12,8'i uyku konusunda yeterli eğitim aldığını ifade ederken, \%29,3’ü bilgi ve deneyiminin yeterli olduğunu belirtmiş̧ir. Yarıdan fazlasının uyku sorunu olan bir hasta ile karşılaştığında konsülte ettiğini ve en çok konsülte edilen bölümün çocuk psikiyatristi ve/veya psikolog olduğu görüldü. Kendi çocuğunda uyku sorunu yaşayan hekimlerin, uyku konusunda aileye daha fazla bilgi verdiği ve hastaları daha sık başka bölümlere konsülte ettikleri görüldü. Sonuç: Ülkemizde çocuklarda uyku konusu arka plana itilmiş bir konu olup çocuklarla ilgilenen hekimlerimiz bu konuda yetersiz kalmaktadır. Anahtar Kelimeler: Çocuk, uyku problemleri, uyku bozuklukları, çocuk hekimleri, aile hekimleri, farkındalık

\begin{abstract}
Objective: Sleep is crucial for development and growth of children. Sleep deprivation or deficiency leads to mortality and morbidity of the children, and influences the life quality of children and their family. Sleep disorders are easily diagnosed by pediatric health care providers, sleep problems may go unrecognized, and treatment and consultations may be insufficient. In the present study we aimed to demonstrate the awareness of pediatric health care providers in regards of child sleep issue.

Materials and Methods: A questionnaire was filled out by pediatricians and family physicians attending to the Symposium of Social Pediatrics.

Results: Of the participating 150 physician, $67.3 \%$ were pediatrician and $32.7 \%$ were family physician. Most of physicians were practicing in training and research hospitals or university hospitals. Of the physicians $65.3 \%$ had one or more children and three out of four $(76.5 \%)$ had their offspring suffering from sleep problems. Most of physicians (87.3\%) spent less than 15 minutes for a patient. It is found out physicians argued sleep issue with a minority of patients. Of the physicians only $12.8 \%$ indicated having sufficient education on sleep, $29.3 \%$ having sufficient knowledge and experience in sleep issue. More than half of the physicians were consulted by a patient suffering from sleep problems and the most consulted departments were child psychiatrist and/or the psychologists. Physicians having offspring suffering from sleep problems were more frequently informed parents in regards of sleep issue and made the patients consult to other departments.

Conclusion: Children's sleep is often an overlooked issue in our country and pediatric health care providers are insufficient about this issue.

Keywords: Children, sleep problems, sleep disorders, pediatricians, family physicians, awareness
\end{abstract}




\section{Giriş}

Uyku, insan hayatı için büyük bir öneme sahiptir. Bu konuda ailelerin yanı sıra sağlık çalışanlarının da bilgi ve deneyiminin olması gerekir. Vizitlerde hekimlerin aileleri sadece hastalık konusunda değil, çocuğun sağlıklı büyüme ve gelişmesi için gerekli konularda da bilgilendirmesi gerekmektedir. Sağlıklı büyüme ve gelişme için aşılama ve beslenme kadar önemli olan bir konu da uykudur.

Bozulmuş veya yetersiz uyku morbidite ve mortaliteye yol açmakta ve hem çocuğun hem de ailenin hayat kalitesini olumsuz etkilemektedir. Uyku apne sendromu, parasomni, narkolepsi ve insomni gibi uyku bozuklukları daha az görülüp tanınması daha kolaydır. Oysa geç uyku saatleri, gece uyanmaları, uyku ilişkili anksiyete, yetersiz uyku ve kötü uyku hijyenini kapsayan uyku problemleri daha sık olmakla birlikte tanısı atlanmaktadır (1).

Ailelerin sağlıklı çocuk izlemlerinde uyku problemlerini problem olarak görmemesi ve hekimle paylaşmaması yanı sıra hekimin bu konuda yeterince eğitimli olmaması ve hastaya ayrılan vaktin yetersizliği vizitlerde uykunun göz ardı edilmesine yol açmaktadır $(2,3)$.

Yapılan çalışmalarda çocuk hastaların görüldüğü kliniklerde uyku konusunun çok az işlendiği, uyku bozuklukları ve problemlerinin tanılarının epidemiyolojik çalışmalardakine göre daha az girildiği ve tedavi önerilerinin yanı sıra konsültasyon oranlarının da çok az olduğu görülmüştür $(4,5)$.

Ülkemizdeki durumun bundan farklı olmadığı düşünülmekle birlikte biz bu çalışmada ülkemizden çocuk sağlığı ile ilgilenen hekim grubunda uyku konusundaki farkındalığı göstermek istedik.

\section{Gereç ve Yöntem}

Sosyal Pediatri Derneği ve Uluslararası Sosyal Pediatri Derneği tarafından 2015'te Ankara'da düzenlenen Sosyal Pediatri Sempozyumu'na katılan çocuk hekimleri ve aile hekimlerine önceden hazırlanmış bir anket formu dağıtıldı. Ankette demografik özellikler, hekimin nerede çalıştığı, çocuğunun olup olmadığı, çocuğunda uyku sorunu yaşayıp yaşamadığı ve yaşadıysa hangi sorun yaşadığı yanı sıra her hastasına ne kadar vakit ayırdığı, vizitlerde hasta ile konuştuğu konular, uyku konusunda aldığı eğitimi yeterli bulup bulmadığı, uyku konusunu aile ile konuşup konuşmadığı, uyku konusunda aileye danışmalık verip veremeyeceği ve hastada uyku sorunu tespit ettiğinde konsültasyon isteyip istemediği ve konsültasyon istemişse hangi bölümden istediği soruldu. Sempozyum çocuk sağlığı izlemi, çocuk sağlığında koruyucu hekimlik gibi konuları kapsamaktaydı. Dolayısıyla katılımcılar da çocuk sağlığı ile ilgilenen bir kitleydi.

\section{İstatistiksel Analiz}

Katılımcılar tarafından doldurulan anket formu SPSS-19 paket programına yüklendi. Istatistiksel analiz yapıldı. Tanımlayıcı özellikler için sayı, yüzdelik ve ortalama kullanıldı. Iki grubun karşılaştııı kabul edildi.

\section{Bulgular}

Çalışmaya yaş ortalaması $34,0 \pm 7,2$ olan $111^{\prime} i$ kadın (\%74), 39'u erkek (\%26) 150 hekim katılmıştır. Hekimlerin \%67,3'ü çocuk hekimi iken; \%32,7'si aile hekimi idi. Hekimlerin \%40,7'si eğitim ve araştırma hastanesinde, $\% 31,3$ 'ü üniversite hastanesinde, $\% 13,3^{\prime}$ ü aile sağlığı merkezinde, $\% 8,7^{\prime}$ 's devlet hastanesinde ve $\% 6^{\prime}$ sı özel hastanede çalışmakta idi.

Hekimlerin \%65,3'ünün çocuğu olduğu ve bunların dörtte üçünün $(\% 76,5)$ çocuğunda uyku sorunu yaşadığı belirtilmiştir. Hekimlerin kendi çocuklarında yaşadıkları uyku sorunlarının sıklığına bakıldığında gece sık uyanma $(\% 65,3)$, geç uyuma $(\% 62,7)$, uykuya dalmada zorluk $(\% 36)$, sabah uyanamama $(\% 18,7)$, ve gündüz uyumama $(\% 6,7)$ olduğu görüldü. Bazı hekimlerin çocuğunda birden fazla sorunla karşıaştığı dikkat çekti.

Çalışmaya katılan hekimlerin $\% 67,3$ 'ü her bir hastasına 10 dakikadan az vakit ayırabilirken, \%20'si 11-15 dakika arası ve $\% 10,7$ 'si 16-30 dakika arasında vakit ayırabilmekteydi.

Hekimlerin hastalarılla hangi konuları görüştüğü soruldu. Beşli Likert skalasına göre görüşme sıklığını sınıflandırmaları istendi. Tablo 1'de özetlendiği gibi hekimlerin yarıdan fazlası hastasıyla enfeksiyonlar, aşılama, beslenme, büyüme ve gelişme konusunu konuşurken, uykuyu hastaların çok az bir kısmıyla konuştuğu görülmektedir.

Hekimlere hastaları sormadan uyku konusunu açıp açmadıkları sorulduğunda \%71, 6'sı olumsuz yanıt vermiştir. Aile sorduğunda ise hekimlerin \%75,7'sinin uyku konusunda aile ile konuştuğu belirtilmiştir.

Hekimlerin uyku konusunda aldığı eğitimin yeterliliği sorulduğunda sadece $\% 12,8^{\prime} i$ yeterli eğitim aldığını ifade ederken, hekimlerin uyku konusunda bilgi ve deneyiminin yeterliliği sorgulandığında ise $\% 29,3$ 'ü bilgi ve deneyiminin yeterli olduğunu belirtmiştir.

Hekimlere uyku sorunu olan bir hastayla karşılaştıklarında başka bölüme yönlendirip yönlendirmedikleri sorulduğunda $\% 65,1^{\prime} \mathrm{i}$ konsülte ettiğini belirtmiştir. Konsülte edilen bölümler Tablo 2'de gösterilmiş̧ir.

Çocuğunda uyku sorunu yaşayan hekimler, yaşamayan hekimlere göre uyku konusunda bilgi ve deneyimleri yüksek olarak belirtilmesine rağmen bu oran istatistiksel olarak anlamlı değildi $(p=0,35)$. Ayrıca çocuğunda uyku sorunu yaşayan hekimlerin,

\begin{tabular}{|l|l|l|l|l|l|}
\hline Tablo 1. Hekimlerin hastalarıla görüştükleri konuların sıklı̆̆ı & Hemen hemen hiçbiriyle \\
\hline Konu & Hemen hemen hepsiyle & Çoğuyla & Yarısıla & Azıyla & Hemen \\
\hline Enfeksiyon & 43,4 & 40,7 & 5,5 & 6,2 & 4,1 \\
\hline Beslenme & 33,8 & 46,9 & 11,7 & 6,2 & 1,4 \\
\hline Aşı & 23,3 & 24,7 & 20 & 25,3 & 6,2 \\
\hline Büyüme-gelişme & 37,2 & 41,4 & 10,3 & 9,7 & 1,4 \\
\hline Uyku & 6,2 & 11,8 & 8,3 & 50,3 & 24,1 \\
\hline
\end{tabular}


aile sormadan ve aile sorduğunda da uyku konusunda aileye daha fazla bilgi verdikleri ve hastaları başka bölümlere daha sık konsülte ettikleri görülmüştür, ancak bu istatistiksel olarak anlamlı değildi $(p>0,05)$.

\section{Tartışma}

Bu çalışmanın sonuçları bize çocuk sağlığı ile ilgilenen hekimlerin uyku konusunda aldıkları eğitimin yetersiz olduğunu, bilgi ve deneyimlerinin az olduğu ve hastalarıyla uyku konusunu pek konuşmadıklarını göstermektedir. Kendi çocuğunda uyku konusunda sorun yaşayan hekimlerin uyku konusunda farkındalıklarının daha yüksek olduğu görülmüştür. Ayrıca hekimlerin hastalarına yeterince vakit ayıramadıkları da dikkat çekmiştir. Uykunun hayatımızdaki önemi ve uyku bozukluklarının yol açtığı etkiler bilindiği halde sağlık çalışanları uykuya gereken ilgiyi göstermemektedir (6).

Yapılan çalışmalarda genel olarak hekimlerin hastalarına ayırdıkları sürenin kısıtlı olduğu görülmektedir (7).

Hammig ve Jozkowski (8) yaptığı bir çalışmada hekimin hastaya ayırdığı sürenin, hastaya verilen sağlık eğitiminin belirleyicisi olduğu ve hastaya ayrılan sürenin kısıtlı olması nedeniyle sağlık eğitiminin de yetersiz olduğu belirtilmiştir.

Bu çalışmada da görüldüğü gibi kısıtlı bir süre zarfında hekimler ailelerle ancak enfeksiyonlar, beslenme, büyüme gelişme ve aşılar gibi en göz önünde olan konuları konuşabilmektedirler. Uyku vizit sırasında enfeksiyon veya büyüme-gelişme, aşı gibi göz önünde olan bir konu olmadığı için aileler de kısıtlı süre zarfında uyku konusunu açmamakta ve çalışmaya katılan hekimlerin bu konuyu aile sormadan açmadıkları dikkat çekmiştir. Ayrıca aile uyku konusunu açtığında bile hekimlerin dörtte birinin aileleri bilgilendirmediği belirtilmiştir. Bilgilendirme yetersizliğinin bir diğer sebebinin çalışmaya katılan hekimlerin uyku konusunda eğitim, bilgi ve deneyimlerinin yetersizliği olduğu düşünülmüştür.

Amerika' da çocuk hekimlerinin vizitlerinin üçte birini sağlıklı çocuk izlemi oluştururken (9) ülkemizde çocuk hekimlerinin sağlıklı çocuk izlemine çok az vakit ayırabildikleri düşünülmektedir. Sağlıklı çocuk izlemini ülkemizde daha çok aile hekimleri, bazı hastanelerinin sosyal pediatri bölümleri ve özel hastaneler ve muayenehanecilik yapan hekimler yapmaktadır.

Çalışmaya katılan hekimlerin uyku konusunda eğitim alıp almadıkları sorulmamıştır. Çalışmadaki hekimlerin uyku konusunda aldığı eğitimin yeterli olduğunu düşünenlerin yüzdesi az olmakla birlikte uyku konusunda kendini yeterli hisseden hekim yüzdesi daha yüksekti. Kendi çocuğunda uyku sorunu yaşayan hekimlerin uykuyu önemli bir çocuk sağlığı konusu olarak gördükleri, uyku konusunda kendilerini geliştirdikleri, ailelerle empati kurdukları ve sorunları çözmek için uğraştıkları görülmüştür. Dolayısıyla bu sonuçlar bize uyku konusunun sadece eğitimle öğrenilmediğini, hekimin kişisel

\begin{tabular}{|l|l|}
\hline $\begin{array}{l}\text { Tablo 2. Uyku sorunu olan çocukların konsülte edildiği bölüm } \\
\text { sıklıkları }\end{array}$ \\
\hline Bölüm & Sıklık (\%) \\
\hline Çocuk psikiyatristi/psikolog & 81 \\
\hline Kulak burun boğaz hekimi & 15,3 \\
\hline Nörolog & 3,7 \\
\hline
\end{tabular}

deneyim, birikim ve ilgisi ile öğrenilebileceğini göstermektedir. Hekimlere uyku sorunlarını ve problemlerini tanıma ve tedavi etme yeterlilikleri tek tek sorulmamakla birlikte kendini uyku konusunda yeterli hissetme sıklığının Owens'in (10) Amerika'da yaptığı çalışmaya katılan hekimlere göre daha düşük olduğu görülmüştür. Ayrıca Amerika'da pediatristler ve aile hekimlerine yapılan uyku ve uyku bozuklukları ile ilgili bir anket sonucunda hekimlerin bu konuda yetersiz olduğu ve uyku konusunda yeterli eğitim almaları gerektiği vurgulanmaktadır $(11,12)$. Bu veriler ışığında ülkemizde ve dünyada çocukla ilgilenen hekimlerin uyku konusunda yeterli olmadığı ve daha fazla eğitime ihtiyaç olduğu söylenebilir (13).

Yapılan çalışmalarda uyku problemleri ve bozukluklarının tanınmasının yetersizliği yanı sıra konsülte edilmesinin ve tedavilerinin de yetersizliği gösterilmiştir $(5,14)$. Bizim çalışmamızda hekimlerin konsültasyon isteme oranlarının azımsanmayacak kadar yüksek olduğu (\%65) görülmüştür. Ancak ailelerin ne kadarının konsülte edildiği bölüme gittiği sorulmamıştır.

Hastaların en çok konsülte edildiği bölüm sorgulandığında büyük çoğunluğunun çocuk psikiyatristine veya psikoloğa gönderildiği dikkat çekmiştir. Ancak ülkemizde çocuk psikiyatristlerinin sayısı yeterli düzeyde değildir. Erişkin hastalar için uyku merkezleri bulunmakla birlikte çocuk hastaların yönlendirileceği uyku merkezleri bulunmamaktadır. Çalışmaya katılan hekimler, danışmanlık verme konusunda yeterli olmadıkları gibi ülkemiz şartlarında bu çocukların yönlendirilebileceği klinikler de yetersizdir. Tıpta uzmanlık kurulunun uzmanlık alanları için belirlediği eğitim programlarında sadece çocuk psikiyatristlerinin eğitim programında uykuya yer verildiği görüldü (15). Tıp eğitimi sırasında uyku konusu işlenmektedir, ancak ülkemizden bununla ilgili bir çalışmaya rastlanmamakla birlikte yurt dışından yapılan çalışmalarda bu eğitimin yeterli olmadığı vurgulanmaktadır (16-18).

\section{Sonuç}

Ülkemizde çocuklarda uyku konusu arka plana itilmiş bir konu olup çocuklarla ilgilenen hekimlerimiz bu konuda yetersiz kalmaktadır. Tıp eğitiminde ve sonraki uzmanlık eğitiminde uyku konusunun hak ettiği yerde olması çocuklarımızın sağlıklı gelişmesi için önemlidir. Hekimlerin çocuk hastalara daha fazla vakit ayırıp çocukların sadece enfeksiyonları ile değil, sağlıklı gelişimleri için gerekli olan konulardan uykuya da yeterli vakit ayırmalıdır. Uyku hijyeni konusunda aileleri bilinçlendirmenin yanı sıra uyku sorunu veya bozukluğu olan hastaları uygun bölümlere konsülte etmelidirler.

Etik

Etik Kurul Onayı: Retrospektif çalışmadır, Hasta Onayı: Alınmamıştır.

Hakem Değerlendirmesi: Editörler kurulu dışında olan kişiler tarafından değerlendirilmiştir.

\section{Yazarlık Katkıları}

Konsept: Suzan Gündüz, Esma Uşak, Dizayn: Suzan Gündüz, Esma Uşak, Veri Toplama veya İşleme: Suzan Gündüz, Esma Uşak, Analiz veya Yorumlama: Suzan Gündüz, Esma Uşak, Literatür Arama: Suzan Gündüz, Esma Uşak, Yazan: Suzan Gündüz. 
Çıkar Çatışması: Yazarlar tarafından çıkar çatışması bildirilmemiştir.

Finansal Destek: Yazarlar tarafından finansal destek almadıkları bildirilmiştir

\section{Kaynaklar}

1. Meltzer LJ, Johnson C, Crosette J, Ramos M, Mindell JA. Prevalence of diagnosed sleep disorders in pediatric primary care practices. Pediatrics 2010;125:e1410-8.

2. Blunden S, Lushington K, Lorenzen B, Ooi T, Fung F, Kennedy D. Are sleep problems underrecognised in general practice? Arch Dis Child 2004;89:708-12.

3. Mindell JA, Moline ML, Zendell SM, Brown LW, Fry JM. Pediatricians and sleep disorders: Training and practice. Pediatrics 1994;94:194-200.

4. Chervin RD, Archbold KH, Panahi P, Pituch KJ. Sleep problems seldom addressed at two general pediatric clinics. Pediatrics 2001;107:1375-80.

5. Meltzer LJ, Plaufcan MR, Thomas JH, Mindell JA. Sleep problems and sleep disorders in pediatric primary care: treatment recommendations, persistence, and health care utilization. J Clin Sleep Med 2014;10:421-6.

6. Meissner $\mathrm{HH}$, Riemer A, Santiago SM, Stein M, Goldman MD, Williams AJ. Failure of physician documentation of sleep complaints in hospitalized patients. West J Med 1998;169:146-9.

7. Halfon N, Stevens GD, Larson K, Olson LM. Duration of a well-child visit: association with content, family-centeredness, and satisfaction. Pediatrics 2011;128:657-64.

8. Hammig B, Jozkowski K. Health Education Counseling During Pediatric Well-Child Visits in Physicians' Office Settings. Clin Pediatr 2015;54:752-8.
9. Abdus S, Selden TM. Adherence with recommended well-child visits has grown, but large gaps persist among various socioeconomic groups. Health Aff 2013;32:508-15.

10. Owens JA. The Practice of Pediatric Sleep Medicine: Results of a Community Survey. Pediatrics 2001;108:e51.

11. Faruqui F, Khubchandani J, Price JH, Bolyard D, Reddy R. Sleep Disorders in Children: A National Assessment of Primary Care Pediatrician Practices and Perceptions. Pediatrics 2011;128:539-46.

12. Papp KK, Penrod CE, Strohl KP. Knowledge and attitudes of primary care physicians toward sleep and sleep disorders. Sleep Breath 2002;6:103-9.

13. Mindell JA, Bartle A, Ahn Y, Ramamurthy MB, Huong HT, Kohyama J, Li AM, Ruangdaraganon N, Sekartini R, Teng A, Goh DY. Sleep education in pediatric residency programs: a cross-cultural look. BMC Res Notes 2013;6:130.

14. Erichsen D, Godoy C, Granse F, Axelsson J, Rubin D, Gozal D. Screening for sleep disorders in pediatric primary care: are we there yet? Clin Pediatr (Phila) 2012;51:1125-9.

15. http://www.tuk.saglik.gov.tr/programlar/prog399.html.

16. Orr WC, Stahl ML, Dement WC, Reddington D. Physician education in sleep disorders. J Med Educ 1980;55:367-9.

17. Rosen RC, Rosekind M, Rosevear C, Cole WE, Dement WC. Physician education in sleep and sleep disorders: a national survey of U.S. medical schools. Sleep 1993;16:249-54.

18. Mindell JA, Bartle A, Wahab NA, Ahn Y, Ramamurthy MB, Huong HT, Kohyama J, Ruangdaraganon N, Sekartini R, Teng A, Goh DY. Sleep education in medical school curriculum: a glimpse across countries. Sleep Med 2011;12:928-31. 